\title{
Colletotrichum truncatum causing anthracnose on papaya fruit (Carica papaya) in Brazil
}

\author{
Willie Anderson dos Santos Vieria ${ }^{1}$. Angélica dos Santos Nunes ${ }^{1} \cdot$ Josiene Silva Veloso ${ }^{1}$. Alexandre Reis Machado ${ }^{2}$. \\ Valdir Queiroz Balbino ${ }^{3}$. Anthony Carlos da Silva ${ }^{1}$. André Ângelo Medeiros Gomes ${ }^{1} \cdot$ Vinson Patrick Doyle ${ }^{4}$. \\ Marcos Paz Saraiva Câmara ${ }^{1}$ (D)
}

Received: 28 June 2019 / Accepted: 16 December 2019 / Published online: 20 December 2019

(C) Australasian Plant Pathology Society Inc. 2019

\begin{abstract}
Papaya anthracnose caused by Colletotrichum truncatum is reported for the first time in Brazil. The etiological agent was identified by a combination of morphological and molecular approaches. Pathogenicity was confirmed and Koch's postulates fulfilled for a selected isolate from Porto Seguro, Bahia, Brazil.
\end{abstract}

Keywords fungal disease $\cdot$ occurrence $\cdot$ postharvest

Papaya (Carica papaya) is among the most widely cultivated and consumed tropical fruits (Serrano and Cattaneo 2010). Among the main producers, México, Brazil, Nigeria, India and Indonesia, Brazil ranked second in 2017 for production volume, producing 1.4 tons on 30.000 ha (IBGE 2017). However, plant diseases lead to reduced productivity in the form of yield loss and have a detrimental impact on fruit quality (Ferreira et al. 2018; Martins and Blum 2014). Papaya yield losses are mainly attributable to phytopathogenic fungi, such as Phytophthora spp., Phoma caricae-papayae, Asperisporium caricae, Oidium caricae, and Colletotrichum spp. (Ventura et al. 2004). Anthracnose is among the most important papaya postharvest diseases due to the large losses in production, which may reach about $90 \%$ (Valenzuela et al. 2015).

In January 2017, a disease was detected causing postharvest losses on papaya in Porto Seguro, Bahia, Brazil. Symptomatic ripe fruit presented brownish, rounded, necrotic and depressed lesions. Black acervuli were produced in

Marcos Paz Saraiva Câmara

marcos.camara@ufrpe.br

1 Departamento de Agronomia, Universidade Federal Rural de Pernambuco, Recife, Brazil

2 Departamento de Micologia, Universidade Federal de Pernambuco, Recife, Brazil

3 Departamento de Micologia, Universidade Federal de Pernambuco, Recife, Brazil

4 Department of Plant Pathology and Crop Physiology, Louisiana State University AgCenter, Baton Rouge, LO, USA lesions as disease progressed and became covered by orange conidial masses. Isolates were obtained from typical anthracnose symptoms using direct isolation by transferring conidial masses from lesions to Petri dishes containing potato dextrose agar (PDA) media supplemented with streptomycin sulfate $(0.03 \mathrm{~g} / \mathrm{L})$. Cultures were incubated at $28^{\circ} \mathrm{C}$ under continuous light. Colony color was characterized seven days after incubation using Rayner's Mycological Colour Chart (Rayner 1970). Mycelial fragments from 7-day-old colonies were mounted in Shear's mounting media to assess micromorphological features, such as conidial shape and size, acervuli, setae, conidiophores, and conidiogenous cells. Pictures were taken with a DS-L3 digital camera attached to a Nikon Eclipse $\mathrm{Ni}-\mathrm{U}$ transmitted light microscope using differential interference contrast illumination. Microscopic image capture and measurement were done using NIS-Elements.

Colonies on PDA presented purplish grey felt-like mycelium with white sectors in aerial view. The reverse was greyish sepia to fuscous black with buff sectors (Fig. $1 \mathrm{c}-\mathrm{g}$ ). Acervuli were present in culture with abundant dark brown, smooth walled, 3-4 septate setae. Conidiophores hyaline to pale brown, septate, branched, smooth-walled. Conidiogenous cells hyaline, smooth-walled, cylindrical, collarette visible. Conidia on PDA were hyaline, aseptate, smooth-walled, falcate, $8.6-(12.5 \pm 1.3)-15.6 \times 3.5-(3.7 \pm 0.4)-5.0 \mu \mathrm{m}$. Morphological features were consistent with Colletotrichum (Sutton 1980). The isolate LM159 was chosen as representative for further analyses. The isolate was deposited at the Culture Collection of Phytopathogenic Fungi "Prof. Maria Menezes" (CMM4878). 
Fig. 1 Papaya anthracnose caused by Colletotrichum truncatum: a typical papaya anthracnose symptoms 4 days after inoculation, b negative control. Colletotrichum truncatum LM159 isolate: 7-dayold culture on PDA (c reverse view, $\mathbf{d}$ aerial view), e papaya fruit naturally infected by Colletotrichum spp., showing typical anthracnose symptoms, $\mathbf{f}$ acervuli, $\mathbf{g}$ conidiophores, $\mathbf{h}$ conidia. Bar, $10 \mu \mathrm{m}$
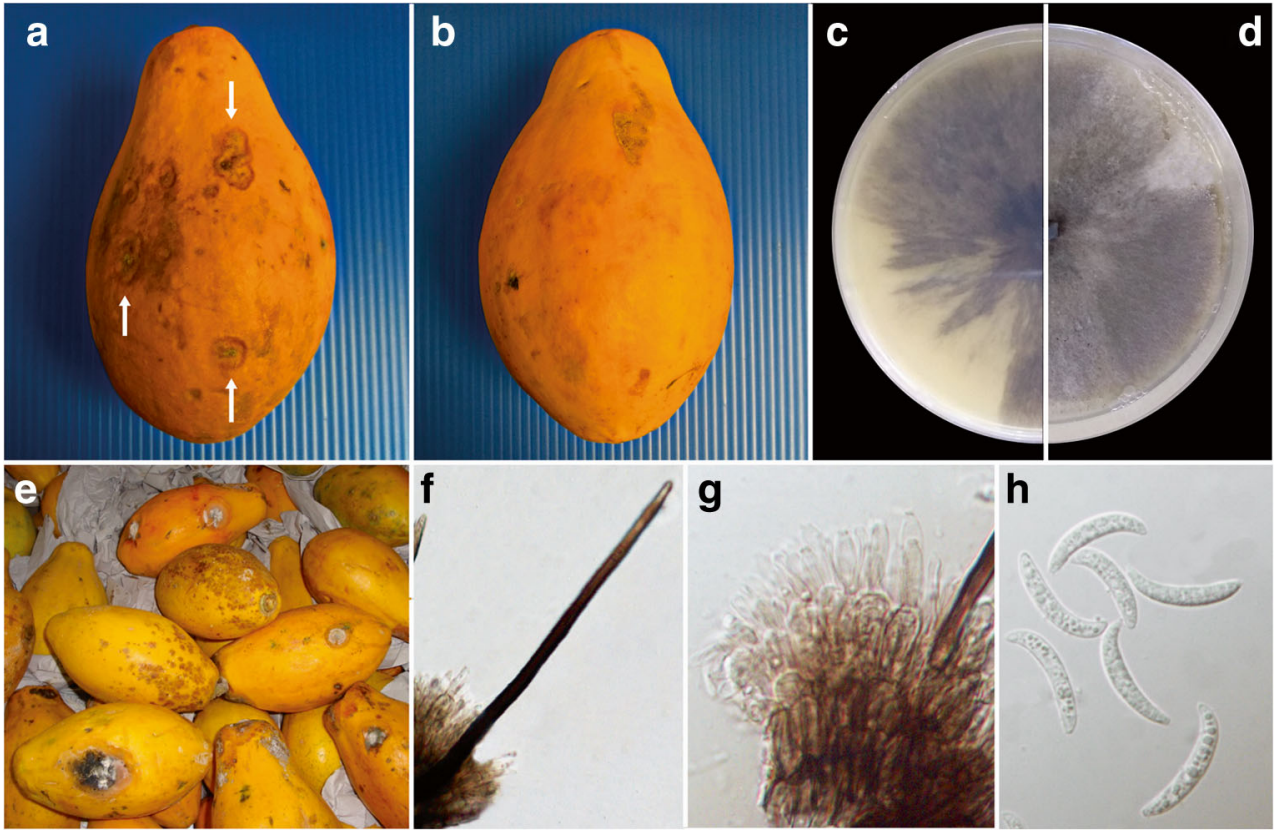

Genomic DNA was extracted from LM159 following the CTAB (cetyl trimethyl ammonium bromide) protocol described by Doyle and Doyle (1990). Partial sequences of glyceraldehyde-3-phosphate dehydrogenase (GAPDH, GenBank accession code MK135782) and $\beta$-tubulin (TUB2, MK135783) were PCR amplified using GoTaq ${ }^{\circledR}$ Master Mix, (Promega Wisconsin, USA). Nucleotide sequences were queried against the NCBI sequence database in order to determine the species complex to which LM159 should be assigned using the BLAST algorithm. LM159 was considered to be in the same species complex as sequences with the highest sequence identity and lowest e-value. Phylogenetic analysis was performed in order to accurately assign LM159 to species. Previously published sequences of ex-type and representative isolates from species within the respective species complex were retrieved from GenBank and aligned using MEGA 7 (Kumar et al. 2016). Individual gene alignments were concatenated in SequenceMatrix v.1.8 (Vaidya et al. 2011) and a maximum likelihood phylogenetic analysis was performed. Phylogenetic analysis was carried out using RAxML 8.2.12 (Stamatakis 2014) under the GTRGAMMA model and support values estimated with 1000 bootstrapped
Fig. 2 Maximum likelihood tree showing relationships among Colletotrichum spp. from the C. truncatum species complex. The tree is rooted with C. curcumae. Bootstrap supports are shown above the branches. Isolate from Carica papaya is highlighted in red

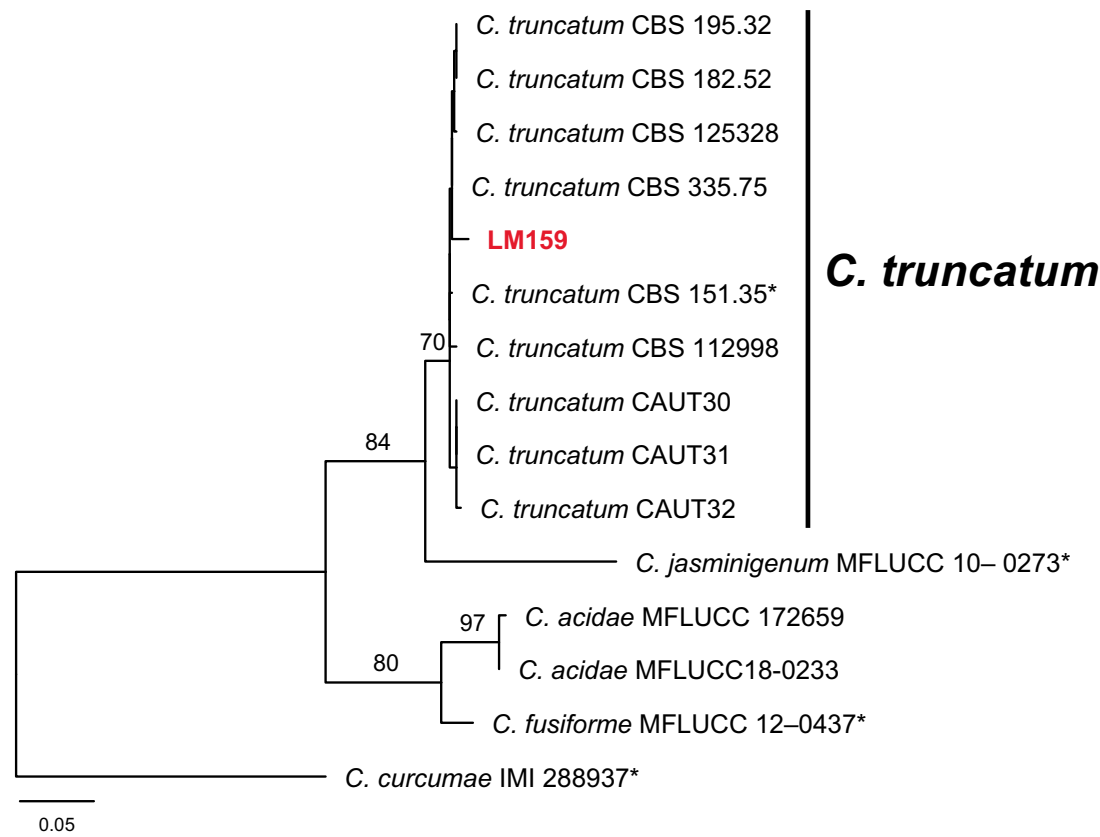


pseudoreplicate datasets (-m GTRGAMMA -p 12345 -k -f a N 1000 -x 12345).

BLAST searches reveal that the sequences of LM159 shared a high sequence identity with species in the C. truncatum species complex. The GAPDH sequence shared $100 \%$ sequence identity (e-value $=3 \mathrm{e}-111)$ with $C$. truncatum sensu stricto LJTJ45 (KP943554), whereas TUB2 sequences were $100 \%$ similar (e-value $=0$ ) to $C$. truncatum $s . s$. COUFAL0018 (MG543283). The papaya isolate grouped in a clade containing the ex-type and representative isolates of C. truncatum with $70 \%$ support in a concatenated analysis (Fig. 2), which confirms LM159 is conspecific with C. truncatum. Morphological features were largely concordant with the description of $C$. truncatum with the exception of conidial length. LM159 had shorter conidia than the type of C. truncatum (21.8 \pm 1.9 on synthetischer nährstoffarmer agar - SNA; $22.9 \pm 1.6$ on Anthrischus stem) (Damm et al. 2009). This variation may be due to the production of LM159 conidia on PDA instead of SNA or Anthriscus stems, or simply represents the variation in conidial dimensions within the species, which is commonly reported among isolates from the same Colletotrichum species.

Koch's postulates were fulfilled to confirm the pathogenicity of LM159. Fruit were washed in running water and surface sterilized in $1.5 \%$ sodium hypochlorite for $3 \mathrm{~min}$, rinsed in sterile distilled water, and air dried. Ten microliters of conidial suspension $\left(10^{6}\right.$ conidia $\left./ \mathrm{mL}\right)$ were deposited at three points on the surface of three papaya fruit. The negative control was represented by fruit inoculated with $10 \mu \mathrm{L}$ of sterile distilled water. Inoculated fruit were kept in a humid chamber for $48 \mathrm{~h}$, $25^{\circ} \mathrm{C}$, and a 12 -h photoperiod. The experiment was repeated 2 times. Typical anthracnose symptoms were observed on the papaya fruit four days after inoculation (Fig. 1a, b). No symptoms were observed on the negative control. The pathogen was reisolated from symptomatic fruit and was morphologically identical to LM159, fulfilling Koch's postulates.

Papaya fruit anthracnose has been associated with C. acutatum (Peres et al. 2002), C. brevisporum (Vieira et al. 2013) and C. karstii (Damm et al. 2009) in Brazil. Colletotrichum truncatum was previously reported causing papaya anthracnose in Korea (Aktaruzzaman et al. 2017), Mexico (Torrez-Calzada et al. 2018) and Trinidad and Tobago (Rampersad 2011), but to our knowledge, this is the first report of $C$. truncatum causing papaya anthracnose in Brazil. Knowledge about new Colletotrichum species in association with papaya anthracnose is important for disease management because different species may react differently according to the control strategies adopted.

\section{References}

Aktaruzzaman M, Afroz T, Lee YG, Kim BS (2018) Post-harvest anthracnose of papaya caused by Colletotrichum truncatum in Korea. European Journal of Plant Pathology 150:259-265

Damm U, Woudenberg JHC, Cannon PF, Crous PW (2009) Colletotrichum species with curved conidia from herbaceous hosts. Fungal Diversity 39:45-87

Doyle JJ, Doyle JL (1990) Isolation of plant DNA from fresh tissue. Focus 12:13-15

Ferreira MS, Malta CM, Bicalho JO, Pimenta RS (2018) A safe method to control the anthracnose in papaya. Revista Brasileira de Fruticultura, v.40 n.3.

IBGE (2017) Instituto Brasileiro de Geografia e Estatística. Available at: http://www.ibge.gov.br. Accessed 15 May 2019.

Kumar S, Stecher G, Tamura K (2016) MEGA7: Molecular Evolutionary Genetics Analysis version 7.0 for bigger datasets. Molecular Biology and Evolution 33:1870-1874

Martins DMS, Blum LSB (2014) Redução da antracnose e da podridão seca pós-colheita em mamão por hidrotermia. Revista Caatinga 27: 98-105

Peres NAR, Kuramae EE, Dias MSC, Souza NL (2002) Identification and characterization of Colletotrichum spp. affecting fruit after harvest in Brazil. Journal of Phytopathology 150:128-134

Rampersad SN (2011) Molecular and Phenotypic Characterization of Colletotrichum Species Associated with Anthracnose Disease of Papaya in Trinidad. Plant Disease 95:1244-1254

Rayner RW (1970) A mycological colour chart. Commonwealth Mycological Institute and British Mycological. Society, Kew

Serrano LAL, Cattaneo LF (2010) O cultivo do mamoeiro no Brasil. Revista Brasileira de Fruticultura, v.32, n.3.

Stamatakis A (2014) RAxML version 8: A tool for Phylogenetic Analysis and Post-Analysis of Large Phylogenies. Bioinformatics 30:13121313

Sutton BC (1980). The Coelomycetes. Fungi Imperfecti with Pycnidia, Acervuli and Stromata. CABI, Kew

Vaidya G, Lohman DJ, Meier R (2011) SequenceMatrix: concatenation software for the fast assembly of multi-gene datasets with character set and codon information. Cladistics 27:171-180

Ventura JA, Costa H, Tatagiba JS (2004) Papaya Diseases and Integrated Control. Diseases of Fruits and Vegetables: Volume II, pp 201-268.

Vieira WAS, Nascimento RJ, Michereff SJ, Hyde KD, Câmara MPS (2013) First report of papaya fruit anthracnose caused by Colletotrichum brevisporum in Brazil. Plant Disease 97:1659 